\title{
Punicic Acid
}

National Cancer Institute

\section{Source}

National Cancer Institute. Punicic Acid. NCI Thesaurus. Code C68420.

A polyunsaturated long-chain fatty acid with an 18-carbon backbone and exactly three double bonds, originating from the 5th, 7th and 9th positions from the methyl end, with these three bonds in the cis-, trans- and cis- configurations, respectively. 